\title{
A CAT Reporter Construct Allows Ultrasensitive Estimation of TNF Synthesis, and Suggests that the TNF Gene has been Silenced in Non-macrophage Cell Lines
}

Bruce Beutier and Tracy Brown

The Howard Hughes Medical Institute, The University of Texas Southwestern Medical Center,

5323 Harry Hines Boulevard, Dallas, Texas 75235

\begin{abstract}
We have prepared a construct (designated CAT $_{\text {TNF}}$ ) in which the mouse TNF (cachectin) coding sequence is replaced by a sequence encoding chloramphenicol acetyltransferase (CAT), with preservation of the TNF promoter and 3 '-untranslated sequences known to be important in the regulation of gene expression. When activated by LPS, permanently transfected RAW 264.7 (mouse macrophage) cells synthesize large quantities of CAT. Unlike TNF itself, CAT is nonsecreted and quite stable in the macrophage cytoplasm. Fewer than 1,000 LPS-induced macrophages can easily be detected by CAT assay. Cells maintain the ability to respond to LPS in vivo; as such, when injected intravenously, they accurately report conditions required for the production of TNF in diverse tissues. These cells may thus be used for the detection of cachectin/TNF synthesis in mice under conditions in which endogenously produced cachectin/ TNF would be undetectable. Studies of the expression of CAT $_{\text {TNF }}$ in nonmacrophage cell lines have revealed that the modified TNF gene is constitutively expressed in L-929 cells, but that its expression is tightly suppressed in HeLa cells and in NIH 3T3 cells. This finding would suggest that certain nonmacrophage cells are potentially capable of utilizing the TNF promoter and translating the TNF mRNA; however, the endogenous gene has been developmentally silenced. (J. Clin. Invest. 1991. 87:1336-1344.) Key words: TNF • reporter construct • chloramphenical acetyltransferase $\bullet$ macrophage $\bullet$ endotoxin • gene regulation
\end{abstract}

\section{Introduction}

It is widely accepted that TNF (also referred to as cachectin) is an important mediator of diverse inflammatory processes. The role of TNF in endotoxic shock has been established both by passive immunization studies (1-3), and by experiments in which the protein was directly administered to animals (4). Similar work has implicated this cytokine in the pathogenesis of cerebral malaria (5), the acute phase of graft-versus-host (GVH) disease (6), bleomycin-induced pulmonary toxicity (7, $8)$, and other disease states as well $(9,10)$. It has been suggested that TNF may play an essential role as a mediator of wasting $(11,12)$ and dyserythropoiesis $(13,14)$ in chronic disease. It is

Address correspondence and reprint requests to Dr. Bruce Beutler, The Howard Hughes Medical Institute, University of Texas Southwestern Medical Center, 5323 Harry Hines Boulevard, Dallas, TX 75235.

Received for publication 15 June 1990 and in revised form 31 October 1990

J. Clin. Invest.

(c) The American Society for Clinical Investigation, Inc.

$0021-9738 / 91 / 04 / 1336 / 09 \$ 2.00$

Volume 87, April 1991, 1336-1344 suspected that TNF may also be involved in numerous chronic inflammatory illnesses, both of infectious and noninfectious etiology.

The sine qua non of "involvement," of course, is the production of TNF. Only if the cytokine is elaborated in a given disease state may it be said to play a role. In many instances, efforts to demonstrate the production of TNF through bioassays or immunologically based assays performed on biological fluids derived from human or animal subjects with various diseases or disease models have yielded negative results, and the presence of the hormone may only be inferred through passive immunization experiments.

It is not possible, for example, to document the presence of TNF in mice infected with Bacillus Calmette-Guerin, or in mice with GVH disease, although passive immunization studies suggest its presence $(6,10)$. It is also impossible to detect circulating TNF in animals with focal infections or inflammatory lesions. This failure might be explained on the basis of several considerations:

(a) TNF, though abundantly produced in response to bacterial endotoxin (11), is produced in far smaller quantities in response to all other known stimuli.

(b) Production is, at least under some circumstances, transient.

(c) A very small volume of tissue may be involved in the inflammatory reaction so that the protein is greatly diluted in the systemic circulation.

(d) The protein is efficiently exported from the cell, leaving little evidence of its production at the secretory site. Thus, immunohistochemical detection of TNF is an exceedingly difficult proposition, further complicated by the fact that an inactive (15) membrane-associated (16) form of TNF has been described.

(e) TNF is produced by extravascular effector cells (chiefly macrophages and, to a lesser extent, lymphocytes), and much of it may never gain access to the circulation.

$(f)$ Circulating inhibitors of TNF, notably a soluble form of the TNF receptor $(17,18)$, have been described, which may interfere with the biological assay of TNF, and perhaps with immunologic detection, as well, under some circumstances.

(g) In circulation, the murine protein has a half-life of $\sim 6$ $\min (19)$.

Attempts to assess the production of TNF by measurement of TNF mRNA in animal tissues have been frustrated by the fact that TNF mRNA can exist in an untranslated form (20); hence, normal tissues contain the mRNA in detectable quantities (21), while there is no assurance that the protein is being synthesized. Indeed, much of the biosynthetic regulation of TNF production has been shown to occur at a translational level in vitro (22).

We considered that many of the problems inherent in the measurement of TNF (and perhaps other cytokines) in vivo 
might yield to the use of a stable, nonsecreted marker, which could faithfully record biosynthesis of the protein. Toward this end, we devised a genetic construct in which the coding sequence of TNF was replaced by a sequence encoding bacterial chloramphenicol acetyltransferase $(C A T)^{1}$. The TNF promoter and TNF 3 -untranslated region were left intact in this construct, in order to assure that the principal regulatory elements required for faithful reproduction of the response to endotoxin (and presumably other stimuli) would be preserved.

We now show that this reporter construct may be used to detect TNF biosynthesis with extremely high sensitivity, both in vitro and in vivo. Moreover, from the fact that the construct is constitutively expressed at high levels in some cells that are incapable of producing TNF, we infer that the TNF gene is developmentally silenced in most tissues. In macrophages, in which the gene is active, reversible suppression of TNF gene expression applies.

\section{Methods}

Construction. A cosmid containing the mouse TNF and lymphotoxin genes was obtained from Ms. K. Blömer of the Howard Hughes Medical Institute, Dallas, TX. This cosmid was digested with KpnI and PstI to produce a 4.45-kb fragment, which was cloned, and then further digested with NarI, yielding a 2,223-nucleotide (nt) span of DNA. The 2,223-nt fragment began in the distal coding sequence of lymphotoxin (exon IV), and continued to a point within the TNF 5'-untranslated region (28 $\mathrm{nt}$ upstream of the initiator 'A'); thus, it contained the TNF promoter (23). This fragment was cloned into Bluescript KS (Stratagene Inc., San Diego, CA) (KpnI $\rightarrow$ Accl).

The Bluescript vector was then cut with SmaI. A previously constructed CAT clone (24) was next employed as a source of the CAT coding sequence. The CAT clone was excised with Sall and BamHI, blunt ended using $S_{1}$ nuclease, and ligated into the Smal site of the above mentioned Bluescript KS vector. The orientation of the CAT coding segment was checked by sequencing.

The Bluescript KS vector, now containing CAT in a position downstream from the TNF promoter and most of the TNF 5'-untranslated region, was cut with $\mathrm{KpnI}$ and ScaI, yielding a 2.9-kb fragment, containing the TNF promoter, most of the TNF 5'-untranslated region, and most of the CAT coding sequence.

Independently, the 3'-untranslated region and DNA sequences extending $\sim 200 \mathrm{nt}$ distal to the poly-A addition site were prepared for cloning. The 4.45-kb KpnI $\rightarrow$ PstI clone was cut with Accl, filled in with the Klenow enzyme, and digested with PstI. This 1,021-nt fragment was cloned into Bluescript KS, which had previously been cut with AccI, blunted with $S_{1}$ nuclease, and recut with PstI. Thus, the AccI sequence in the 3'-untranslated region of the marker clone was identical to that found in the genomic sequence.

The Bluescript vector containing the downstream element was linearized with AccI. Unphosphorylated synthetic linkers, designed to connect the KpnI $\rightarrow$ Scal fragment (containing the promoter $\rightarrow$ CAT complex) to the downstream element, thus repairing the CAT coding sequence, were ligated to the AccI site. The vector was then cut with $\mathrm{KpnI}$, and the 2.9-kb KpnI $\rightarrow$ Scal fragment was cloned into it, completing the construct.

Shown in its final form in Fig. 1, the construct is 3,963 bp in length. The CAT coding sequence exactly replaces the TNF coding sequence, with the exception of a linker sequence $\left(\left[5^{\prime} \rightarrow 3^{\prime}\right]\right.$ ACGGTATCGA TAAGCTTGAT ATCGAATTCC TGCAGCCCCC GAGCTCCCCT CGACGAGATT TTCAGGAGCT AAGGAAGCTAAA), which mod-

1. Abbreviations used in this paper: CAT, chloramphenicol acetyltransferase; nt, nucleotide. ifies the $5^{\prime}$-untranslated region, replacing the $28 \mathrm{nt}$ upstream from the start codon.

For some studies, a promoterless version of the construct was used. The TNF promoter was deleted from the construct by cleaving the construct with KpnI and ClaI (a unique site within the linker), blunting the ends, and religating.

Cell culture. RAW 264.7 cells, obtained from the American Type Culture Collection, were grown in DMEM supplemented with $5 \%$ fetal bovine serum (Gibco Laboratories, Grand Island, NY). Cells were split when they reached confluence by rinsing them with Dulbecco's PBS and allowing them to soak in a second change of PBS for several minutes, after which they were readily removed from the plate by trituration. L-929 cells (to be used both for transfection and for the TNF bioassay), HeLa cells, and NIH3T3 cells were grown in DMEM supplemented with $10 \%$ FBS.

Penicillin and streptomycin solution (Gibco Laboratories) were added to all cultures at a final concentration of $4 \%$.

Transfection. RAW 264.7 cells were transfected as described elsewhere (22). $10 \mu \mathrm{g}$ of vector containing the CAT marker and $10 \mu \mathrm{g}$ of pSV2neo were mixed and precipitated with calcium phosphate. $10^{6}$ cells were transfected, subjected to glycerol shock, and allowed to recover for $48 \mathrm{~h}$. Selection with $\mathrm{G} 418(1 \mathrm{mg} / \mathrm{ml})$ was carried out over the next 3 wk, by which time visible colonies had formed.

HeLa cells, L-929 cells, and NIH3T3 cells were transfected using the technique described by Chen and Okayama (25). The same quantity of DNA was employed as in the case of RAW 264.7 cell transfections. Pooled G418-resistant clones were used for CAT assay. DNA was prepared from these cell types to document that reporter gene transfection had occurred.

Induction of TNF and CAT expression by LPS. E. coli LPS (strain 0127:B8) was obtained from Gibco Laboratories. Cells were induced by adding LPS to a final concentration of $1 \mu \mathrm{g} / \mathrm{ml}$ unless otherwise noted, for the stated period of time.

TNF bioassay. Bioassay of TNF produced by transfected RAW 264.7 cells, or TNF present in serum, was carried out as previously described (15) in 96-well plates using cycloheximide $(0.1 \mathrm{mg} / \mathrm{ml})$ to potentiate the cytotoxic effect. Cytotoxicity was assessed by staining the residual cells with crystal violet. Measurements were performed using a microplate reader and interpreted with reference to a standard preparation of recombinant human TNF.

In vivo studies of CAT synthesis. Female BALB/c mice, $\sim 25 \mathrm{~g}$ each, were used in these experiments.

RAW 264.7 cells bearing the CAT construct were chromium labeled for a period of $10 \mathrm{~min}$ at room temperature, and washed twice before intravenous injection into animals; $2 \times 10^{7}$ cells were injected per mouse. In preliminary experiments, distribution of the chromium label was followed over time; in subsequent experiments, some of the mice were injected intraperitoneally with $500 \mu \mathrm{g}$ of LPS (approximately one LD50 dose) $2 \mathrm{~h}$ after injection of the cell suspension; controls received no injection. The animals were bled and then killed by $\mathrm{CO}_{2}$ narcosis $4 \mathrm{~h}$ later.

Tissues were weighed upon removal, homogenized in $0.25 \mathrm{M}$ Tris, pH 7.8, frozen, thawed, and centrifuged at $12,000 \mathrm{~g}$ to remove insoluble material. The supernatant was then assayed for protein, and subsequently heated to $65^{\circ} \mathrm{C}$ for $5 \mathrm{~min}$. After a second centrifugation, the supernatant was subjected to CAT assay and counted to quantitate the chromium label.

CAT assay. The thin layer chromatography procedure of Gorman, et al. (26) was used to measure CAT activity in cell lysates, derived from either peritoneal tumors or from cultured cells.

DNA isolation. DNA was prepared from transfected cells as elsewhere described (27).

Measurement of the half-life of CAT synthesized within RAW 264.7 cells. Cultured cells were plated in 3-cm dishes, rinsed with DMEM, and then overlayed with prewarmed medium containing $\left[{ }^{35} S\right]-$ methionine (Amersham Corp., Arlington Heights, IL) and LPS. After a 4-h incubation, cells were washed with prewarmed DMEM containing unlabeled methionine, supplemented with 5\% FBS, and either main- 
tained in the presence or absence of LPS. Cells were harvested by trituration with PBS, pelleted, and resuspended in a solution containing $140 \mathrm{mM} \mathrm{NaCl}, 1.5 \mathrm{mM} \mathrm{MgCl}_{2}$, and $10 \mathrm{mM}$ tris, $\mathrm{pH}$ 8.6. The cells were then lysed by the addition of an equal volume of the same solution containing $1 \%$ NP40. The nuclei were removed by centrifugation, and rabbit anti-CAT serum ( $2 \mu \mathrm{l}$; obtained from $5^{\prime} \rightarrow 3^{\prime}$, Inc.) was added to each sample for a period of $2 \mathrm{~h}$ at $0^{\circ} \mathrm{C}$, followed by pansorbin (Calbiochem-Behring Corp., San Diego, CA; $30 \mu \mathrm{l}$ of a $10 \%$ suspension). The pansorbin was pelleted after an additional $1 \mathrm{~h}$ of incubation, resuspended in $1 \mathrm{ml}$ of PBS containing $0.25 \%$ SDS, then repelleted and washed five times with a solution containing $10 \mathrm{mM}$ tris, $\mathrm{pH} 7.5,150$ $\mathrm{mM} \mathrm{NaCl}, 10 \mathrm{mM}$ EDTA, $0.25 \% \mathrm{SDS}$, and $0.5 \%$ NP40. The pellet was then washed a final time in PBS, pelleted, and resuspended in $40 \mu \mathrm{l}$ of $10 \mathrm{mM}$ tris, $1 \mathrm{mM}$ EDTA solution. After addition of $40 \mu \mathrm{l}$ of SDS sample buffer, each sample was boiled for $5 \mathrm{~min}$ and subjected to electrophoresis in a polyacrylamide gel (28), poured as a $10-15 \%$ gradient. The gel was soaked in Enlightening (DuPont Co., Wilmington, DE), dried, and used for autoradiography. Densitometric analysis of the exposed film was carried out using a Gilford Response spectrophotometer (C. N. Wood Manufacturing Co., Newtown, PA).

\section{Results}

The construct employed in these experiments is illustrated in Fig. 1. It contains sequence encoding the last 135 amino acid of the lymphotoxin protein, the lymphotoxin 3 -untranslated region, the DNA sequence lying between lymphotoxin and TNF (which contains the TNF promoter), most of the 5'-untranslated sequence derived from TNF, a short linker connecting the TNF 5'-untranslated region to CAT, the CAT coding sequence, the 3'-untranslated sequence of TNF, and $\sim 200$ bp of DNA lying downstream from the poly-A signal sequence. Thus, all of the principal regulatory elements presently known to affect TNF synthesis are included.

Transfection of $R A W 264.7$ cells with $C A T_{T N F}$. After cotransfection of this construct (together with pSV2neo) into RAW 264.7 cells, G418 selection was performed, and a pool of resistant cells was obtained from $\sim 40$ primary clones. Highly inducible expression of CAT was observed in the pool after exposure to endotoxin; the ratio of CAT activity (induced/noninduced) was $\sim 4,000: 1$. Subclones of the pool were obtained by limiting dilution of the parent culture, and many were found to be similarly inducible (Fig. 2). Clone 23 was selected

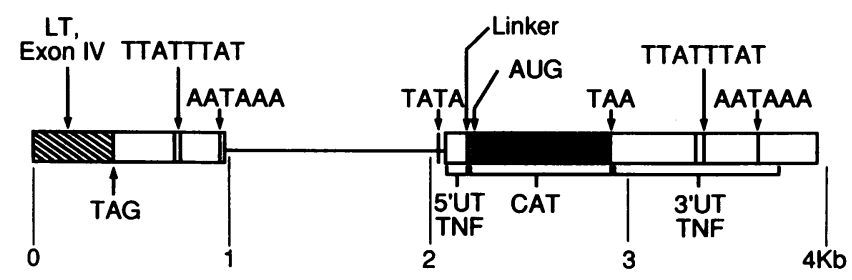

Figure 1. The CAT construct used as a reporter of TNF biosynthesis. For most applications, the construct was cloned into the vector Bluescript $\mathrm{KS}$ between $\mathrm{KpnI}$ and Smal sites. $5^{\prime}$ sequences from the CAT genblock preceed the initiation codon of CAT, and replace some of the 5'-untranslated sequence of TNF as described in the text. The 3 -untranslated region of mouse TNF was inserted exactly after the termination codon of CAT (e.g., the termination codons of TNF and CAT are superimposed). Solid bar, CAT sequence; open bars, untranslated sequences of TNF and lymphotoxin genes; hatched bar, lymphotoxin coding sequence. for all of the experiments described below. By Southern blot analysis, it was found to contain $\sim 10$ copies of the marker gene per genome (Fig. 3).

Induction of CAT biosynthesis by endotoxin. Endotoxin induces CAT expression in RAW 264.7 cells over a period of time similar to that required for TNF induction (Fig. 4). Cellassociated CAT activity declines after $16 \mathrm{~h}$ in the presence of endotoxin (not shown). However, measurements of CAT activity in the culture medium suggest that this may be partly attributable to cell lysis. Indeed, LPS is known to exert a strong cytotoxic effect upon RAW 264.7 cells (29). The biosynthesis of CAT also mimics TNF production by a culture when examined with respect to endotoxin concentration; exposure of cultured cells to increasing quantities of LPS led to the coordinate induction of CAT and TNF (Fig. 5). In neither case was the relationship between CAT and TNF perfectly linear; this may be explained, in part, by the fact that TNF is cleared from a culture by binding to its cell-surface receptor. CAT activity was induced in the cultures by concentrations of LPS that were insufficient to induce the secretion of detectable quantities of TNF. Thus, the CAT assay is a more sensitive indicator of macrophage activation than the TNF bioassay.

The quantity of CAT present in RAW 264.7 cells was such that 1,000 maximally-induced cells could be detected by a $2-\mathrm{h}$ CAT assay, with an overnight exposure of the film (Fig. 6).

The half-life of CAT within cultured RAW 264.7 cells was determined by pulse labeling during a 4-h period of exposure to LPS, with immunoprecipitation of the labeled product at various times thereafter. After labeling, cells were maintained in the presence or absence of LPS (Fig. 7). In either case, densitometric data (not shown) indicated that CAT was cleared from the cytoplasm with biphasic kinetics: an initial rapid loss of CAT protein $\left(t_{1 / 2}\right.$ of $1-2 \mathrm{~h}$ ) was followed by a slow phase of loss $\left(t_{1 / 2}\right.$ of 10-20 h), suggesting that distinct pools of the reporter might exist within these cells.

In short term experiments, transfected RAW 264.7 cells report the biosynthesis of TNF in vivo. In order to utilize the transfected RAW 264.7 cells as a reporter of TNF biosynthesis in vivo, cultured cells were chromium labeled and injected intravenously into BALB/c mice. The majority of the cells were recovered from the lung $30 \mathrm{~min}$ after injection; however, redistribution occurred so that within $2 \mathrm{~h}$, many of the cells had migrated to the liver, spleen, and other organs (data not shown). When mice were injected with LPS subsequent to infusion of the reporter cells, and then sacrificed several hours later, strong induction of CAT activity was observed in many of the organs examined (Fig. 8). Control mice which did not receive LPS failed to express detectable quantities of CAT in any of their tissues. Interestingly, CAT expression was easily detected in animals at time points during which serum TNF activity in mice, as in all other species thus far examined, would ordinarily have declined to levels that were nearly undetectable $(3,19,30-33)$. This presumably reflects the high stability of this nonsecreted marker after its expression in vivo.

L-929 cells express the CAT $T_{T N F}$ gene constitutively at high levels; in other cell lines, the reporter is silent. L-929 cells expressed CAT constitutively when permanently transfected with the reporter construct (Fig. 9 a). This result was observed in each of three separate transfections both with pooled clones and with individual subclones. HeLa cells and NIH3T3 cells, however, failed to express CAT, although permanently transfected cell pools clearly contained the CAT gene, as indicated 

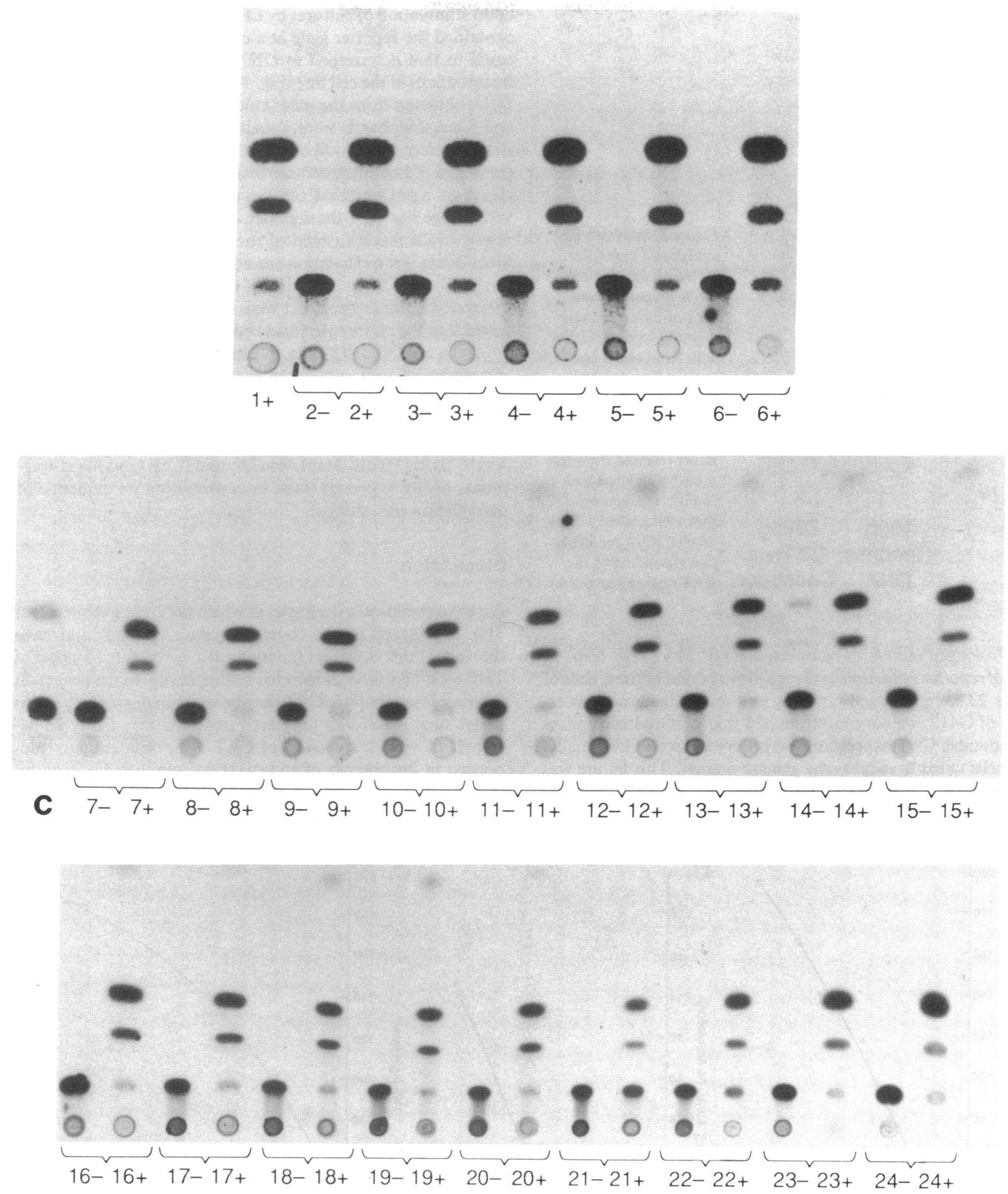

Figure 2. Induction of 24 independent transfected RAW 264.7 cells clones by LPS. 100,000 cells from each clone were cultured overnight in the presence $(+)$ or absence $(-)$ of LPS; the cells were then assayed for CAT activity. The noninduced sample derived from clone 1 was omitted from the assay. $C$, positive control (10 mU CAT added to the assay system).

by Southern blot analysis (Figs. $9 a$, and $b$ ). At the level of mRNA expression, the endogenous TNF gene appears silent in each of these lines (Fig. 9 c). Moreover, no TNF secretion may be detected by bioassay (not shown).
When L-929 cells were transfected with a promoterless version of the CAT construct, no CAT activity was observed, indicating that expression of the construct did not result from fortuitous insertion near an endogenous promoter (not shown). 


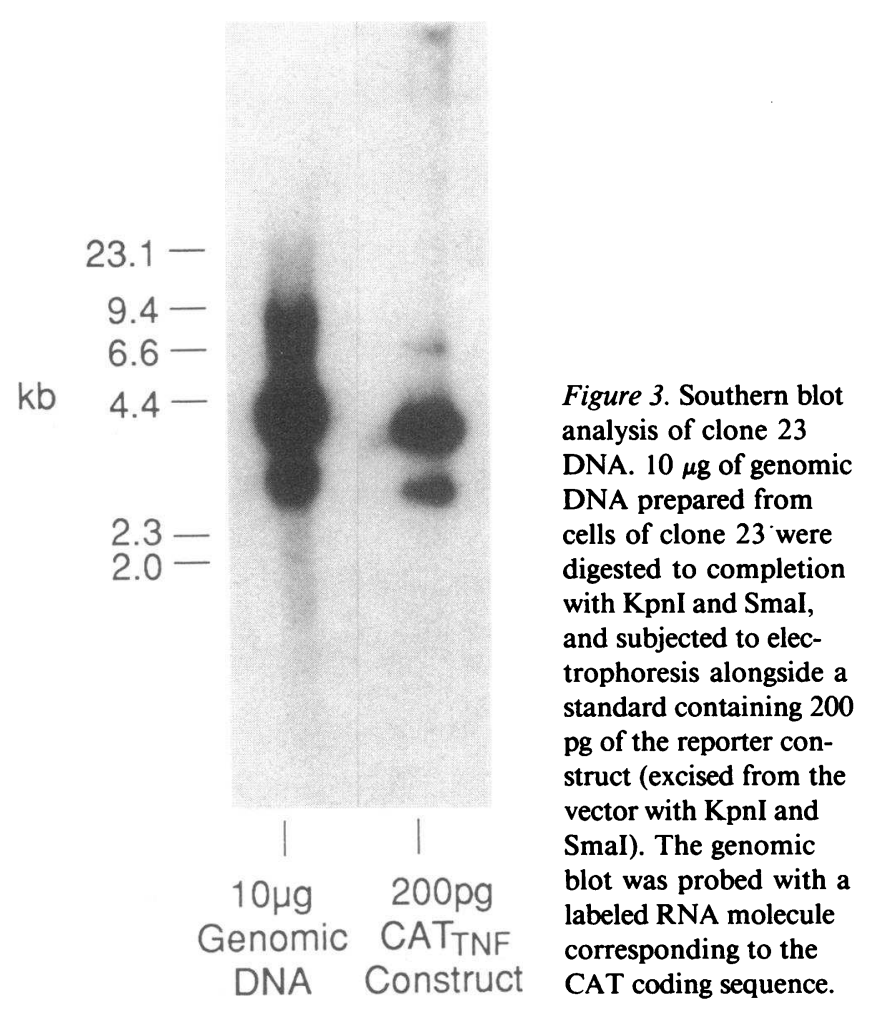

Prolonged culture of transfected RAW 264.7 cells leads to loss of reporter inducibility. Over a 4-mo period of time, cells of clone 23 were passaged biweekly and maintained in the presence of G418 at a concentration of $1 \mathrm{mg} / \mathrm{ml}$. Gradually, a loss of inducible CAT expression was observed, so that eventually, the cells failed to express the genetic marker. This failure was not attributable to an LPS-refractory state: TNF was released upon stimulation of cultures by LPS (not shown). The cells still contained the reporter gene at a copy number approximately equal to that determined in DNA prepared from recultured frozen stocks of the cell line (Fig. 10). However, when genomic DNA obtained from the older culture was digested with KpnI and SmaI, two bands were visualized; cells frozen at an early stage of culture displayed only one band. The size of the bands $(\sim 4$ and $7 \mathrm{~kb}$ ) suggested an explanation, in that failure to cleave at KpnI or SmaI sites would lead to excision of the vector together with the reporter construct (e.g., a 7-kb fragment would result instead of the expected 4-kb fragment). Since Smal is a methylation-sensitive enzyme, we have tentatively concluded that a fraction of the SmaI sites present in the integrated reporter construct were methylated, and further inferred that the entire insert had been modified by methylation.

HeLa and NIH3T3 cells, in which the reporter construct is not expressed, were subsequently examined for evidence of insert methylation using a panel of methylation-sensitive enzymes, although no indication of SmaI site methylation was apparent (Fig. 9 b). All of the enzymes tested (AccI, AvaI, AvaII, BglII, HpalI, MspI, Sau3A, and XbaI) produced fragments of the expected sizes, thus providing no evidence of methylation (not shown).

\section{Discussion}

We have produced a construct in which the coding sequence of TNF is replaced by the coding sequence of CAT, and have shown that this construct functions as a nonsecreted marker of TNF biosynthesis in transfected macrophages. In the near term following transfection, CAT may be measured with high sensitivity, such that 1,000 fully activated cells may easily be detected. In vitro, expression of CAT activity is strongly suppressed in the absence of an activating stimulus. Thus, an induction ratio of 4,000 is observed in the most inducible
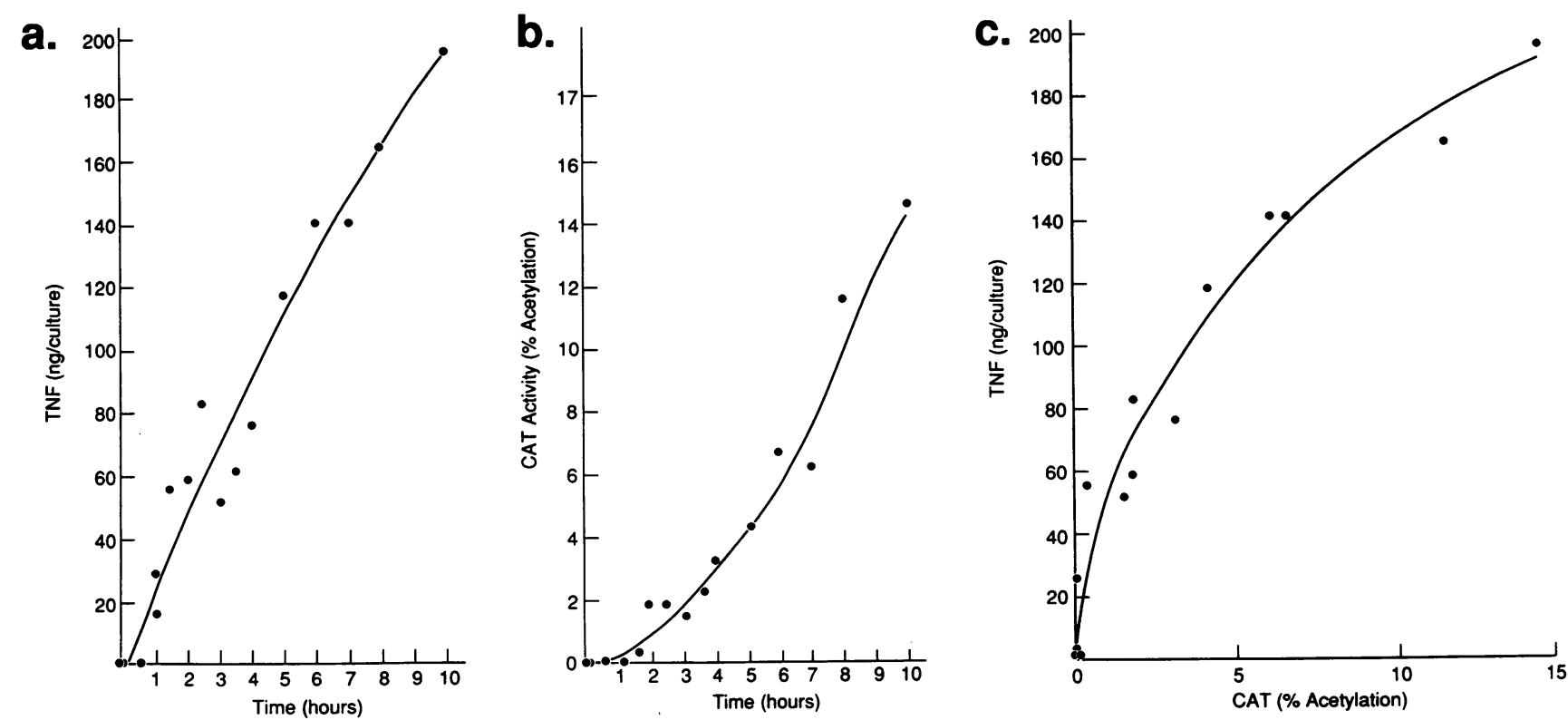

Figure 4. Time-dependent expression of CAT and TNF activity by clone 23 RAW 264.7 cells. All cells were exposed to LPS at a concentration of $1 \mu \mathrm{g} / \mathrm{ml}$ for varying periods of time. (a) TNF secretion by cultured cells increases with time after activation by this maximally inducing concentration of LPS. (b) CAT activity in the same cultured cells. (c) Correlation of CAT activity and TNF activity produced by each culture. 

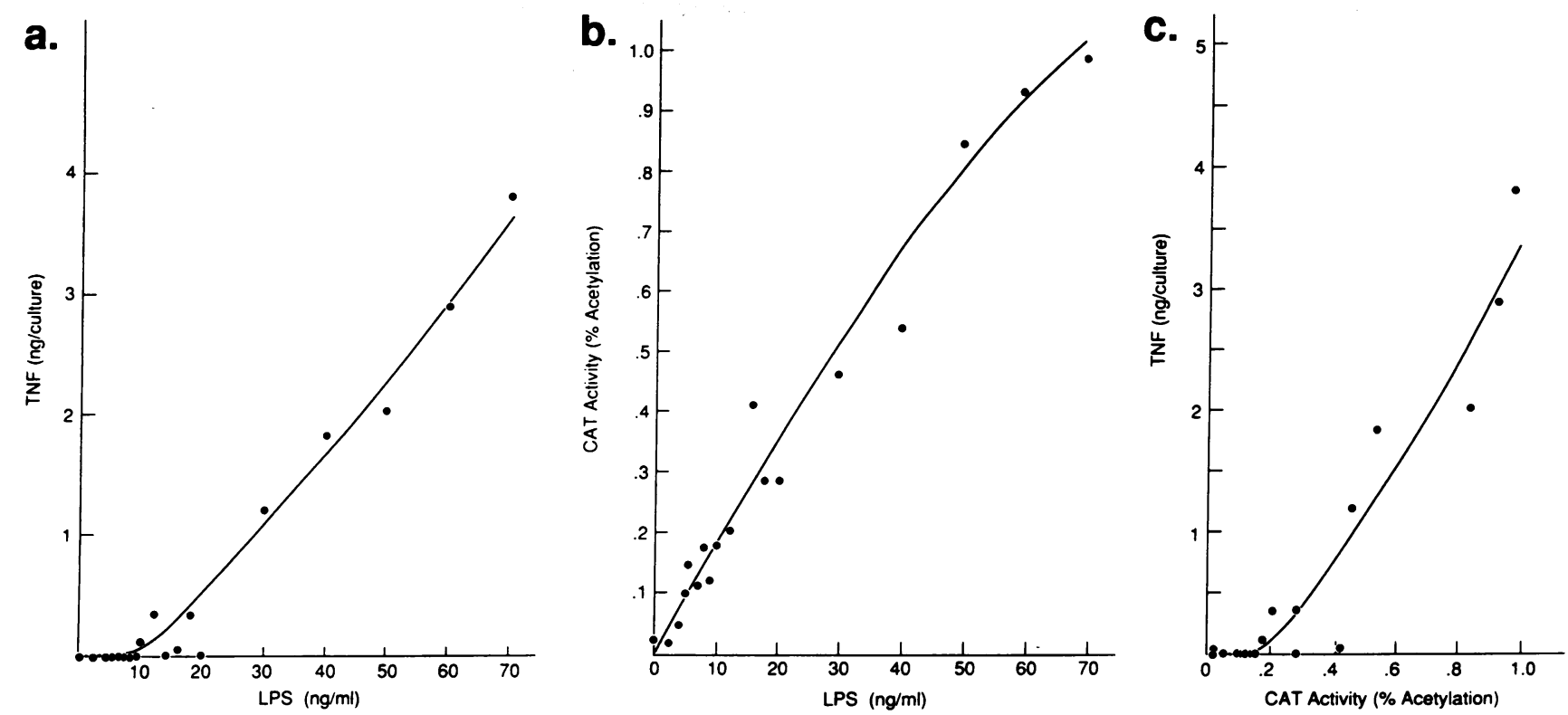

Figure 5. LPS-dependent expression of CAT and TNF activity by clone 23 RAW 264.7 cells. All cells were cultured in the presence of LPS (at varying concentration) for a period of $16 \mathrm{~h}$. (a) TNF secretion by cultured cells exposed to varying concentrations of LPS. (b) CAT activity in the same cultured cells. $(c)$ Correlation of CAT activity and TNF activity produced by each culture.

subclones tested. We have shown that such cells can function in vivo as reporters of conditions required for the biosynthesis of TNF. Since the reporter enzyme is nonsecreted and quite stable, it can be measured under conditions in which TNF cannot normally be detected. Thus, when the cells are injected into mice by an intravenous route, they report activation with a strong signal, apparent in tissues after serum TNF levels have peaked and declined to undetectable values.

In the course of our studies, several interesting observations pertinent to the regulation of TNF gene expression have emerged:

(a) As noted above, the reporter construct is constitutively expressed in L-929 cells after transfection. LPS does not significantly influence CAT gene expression in these cells. Interestingly, expression occurs despite the fact that the authentic TNF gene is entirely silent. This suggests that the authentic TNF gene has been inactivated in these cells (as indeed it may be

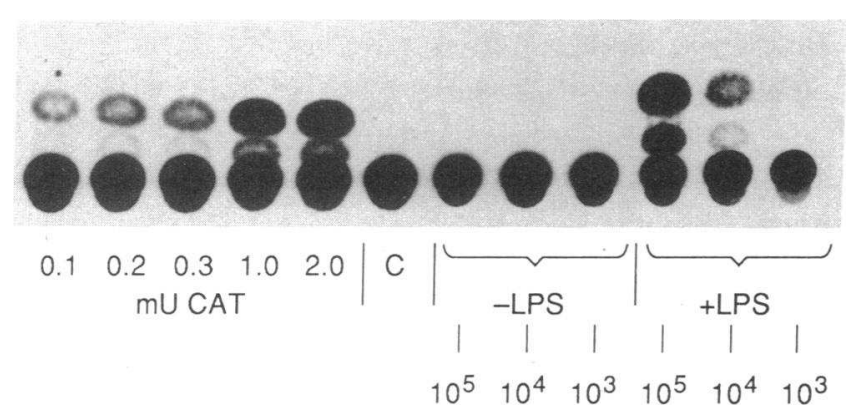

Figure 6. Sensitivity of CAT detection in clone 23 RAW 264.7 cells. A CAT activity standard (0.1-2.0 mU CAT) was included in the assay, as was a sample from which CAT was omitted $(C) .1,000-100,000$ noninduced (-LPS) or fully activated (+LPS) cells were included in each assay system. Cells were activated by incubation with LPS (1 $\mu \mathrm{g} / \mathrm{ml}$ ) for a period of $16 \mathrm{~h}$. during the development of many somatic tissues); however, the factors required for transcription and translation of the unmodified reporter gene remain intact.

(b) In RAW 264.7 macrophages, the reporter gene (like the TNF gene that it was designed to mimic) is strongly suppressed in unstimulated cells, but is readily induced by endotoxin. Taken together with other data suggesting the existence of suppressor mechanisms regulating the expression of TNF at both transcriptional (34) and translational levels $(20,23)$, it may be concluded that TNF gene expression is reversibly suppressed in macrophages; however, mechanisms that promote derepression may be activated by LPS.

(c) In HeLa cells, and in NIH3T3 cells, neither the reporter gene nor the authentic TNF gene are expressed, either in the absence or presence of LPS. The status of the authentic TNF gene, with respect to developmental inactivation, cannot readily be established in these cell types. However, the inactivity of the reporter gene (despite a lack of evidence of methylation) is curious, and suggests that in these cells, as in macrophages, a system for the repression of TNF biosynthesis may be in place. It may further be assumed that the activating mechanism normally triggered by LPS is not functional.

Thus, two general mechanisms of TNF gene repression seem to apply in somatic cells. One appears to have a developmental basis, and is not reversed by treatment with LPS. The second repressor mechanism may apply in many tissues; it exhibits both transcriptional $(34)$ and translational $(23,35)$ components, is reversed by treatment with LPS in macrophages (which undergo numerous changes in response to this stimulus), but not reversed in HeLa cells or NIH 3T3 cells (which at least in this respect, are quite indifferent to LPS).

Certain lines of evidence suggest that the silence of the TNF locus in tissues that fail to express the protein is based upon methylation of the gene. Methylation of the lymphotoxin gene (adjacent to the cachectin/TNF gene) appears to take place in at least some tissues that are incapable of expressing the gene 


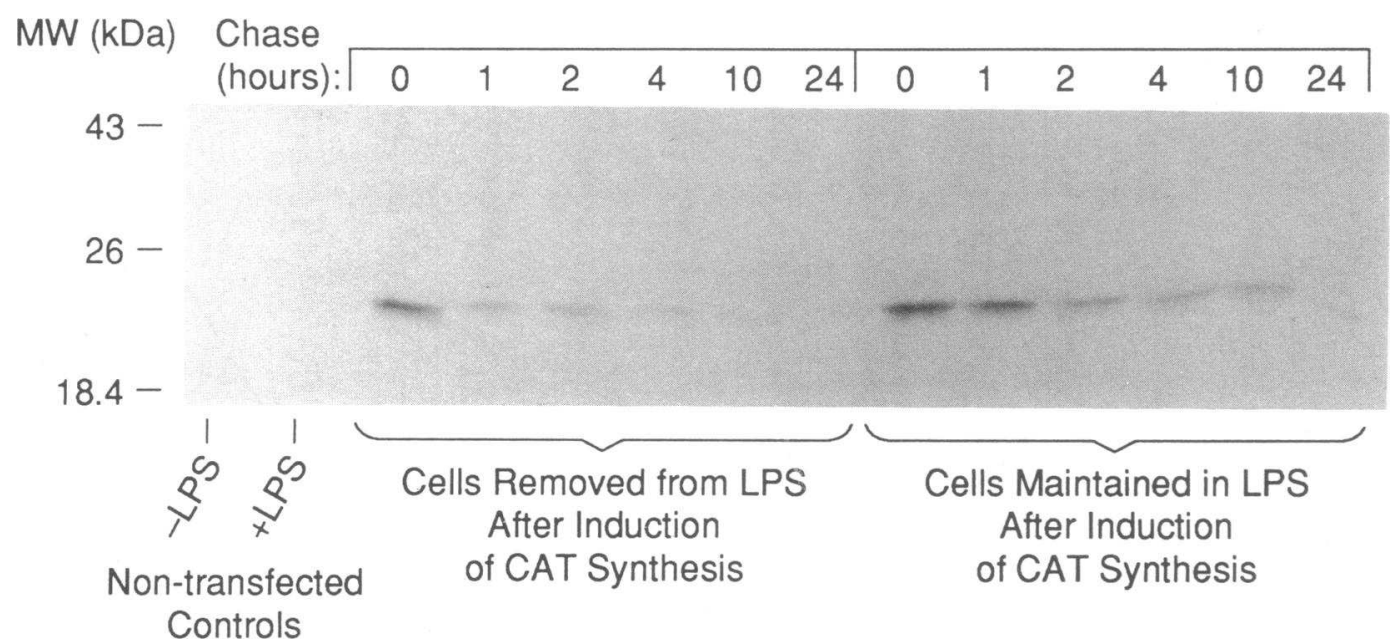

Figure 7. Determination of the half-life of CAT in transfected RAW 264.7 cells by pulse labeling with $\left[{ }^{35} S\right]$ methionine. Detectable quantities of immunoprecipitable CAT were present in the cells $24 \mathrm{~h}$ after labeling whether or not cells were maintained in the presence of LPS. Nontransfected controls: RAW 264.7 cells that had not been transfected with the CAT construct were either induced or left noninduced in the presence of $\left[{ }^{35} S\right]$ methionine, and used in the immunoprecipitation assay immediately after the labeling period. (e.g., neutrophils) as assessed by restriction analysis (36). It is interesting to note that the reporter construct was, with the passage of time, apparently methylated in a similar fashion. Conceivably, certain structural features of the TNF gene invite methylation under conditions that have yet to be determined. Alternatively, the location of the insert may have predisposed to inactivation in this particular clone.

As to reversible repression of TNF gene expression, Shakhov et al. (15) and Collart et al. (37) have noted the presence of NFKB sites in the TNF promoter, and it has been suggested that $\mathrm{NF}_{\kappa} \mathrm{B}$, together with $\mathrm{I} \kappa \mathrm{B}$, comprise a system for the modulation of TNF gene expression, as it occurs in response to protein kinase $\mathrm{C}$ activation (38). If this mechanism of derepression occurs at the transcriptional level, it must be inferred that $N F \kappa B$ is not fully suppressed by $I_{\kappa} B$ in L-929 cells, in which the reporter is constitutively produced. Indeed, it would be of interest to determine whether expression of CAT is subject to a

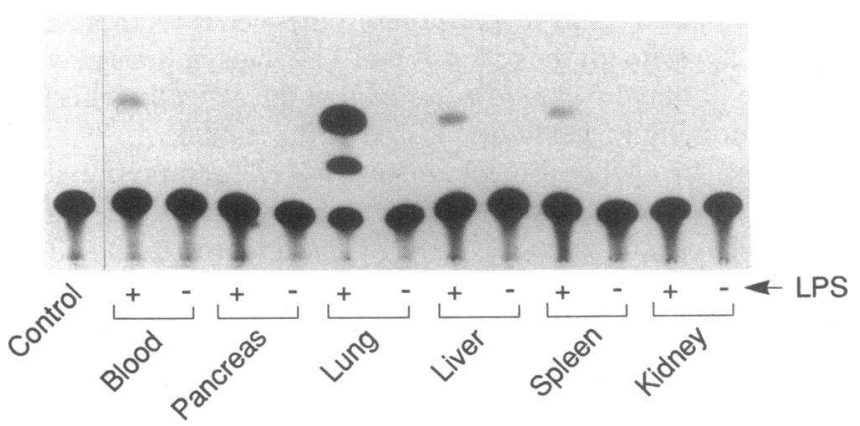

Figure 8. Expression of CAT activity by clone 23 cells after infusion in vivo. Two balb/c mice were injected intravenously with a suspension of $2 \times 10^{7}$ chromium-labeled reporter cells. $2 \mathrm{~h}$ later, one of the mice $(+)$ was injected with $0.5 \mathrm{mg}$ of LPS intraperitoneally, while the other was left uninjected $(-)$. Organs were harvested for estimation of CAT activity. A 2-h CAT assay was performed and the TLC plate was exposed to the film overnight. suppressive influence that is dominant in trans, as the I $\kappa$ B:NF $\kappa$ B model would suggest; alternatively, a dominant activator might be at work. A distinction between these possibilities might be made through the use of somatic cell hybrids.

The translational component of reporter gene activation contributes, in our construct, to the induction of CAT biosynthesis. While promoter-CAT constructs transfected into RAW 264.7 cells are usually capable of generating 50 -fold induction of synthesis in response to LPS (not shown), a far higher induction ratio is witnessed after inclusion of the 3 '-untranslated region (e.g., 4,000-fold in this study). Conceivably, other elements of the TNF gene, contained within the introns, might further augment the response.

The genetic marker that we have produced and characterized affords many opportunities in TNF research. It may, for example, facilitate the study of macrophage responses and the analysis of permanent macrophage cell lines. It may also help to clarify whether certain other cell types can, in fact, produce TNF, and may serve as a signpost of macrophage differentiation. Of still greater importance, however, is the potential use of this construct, or a similar one in transgenic animals, in which it may faithfully report the production of TNF whenever and wherever it occurs in vivo.

Among many questions that might be answered through the use of CAT $\mathrm{TNF}_{\mathrm{TNF}}$ constructs, it may be possible to ascertain the principal tissue sources of TNF as it is produced in endotoxemic animals. It will be possible to examine the autonomous production of TNF by tumors or by immune cells reacting to tumors. It may also be possible to determine whether the protein is produced in various inflammatory diseases, both acute and chronic in character, and in diseases in which inflammation occurs in an anatomically restricted pattern (e.g., focal infections and circumscribed autoimmune processes). The full range of cells capable of elaborating TNF under physiologic conditions and the production of TNF during development might also be assessed. It must be noted of course, that tissuespecific expression of the construct in transgenic animals might well depend upon sequences that reside within introns, within 

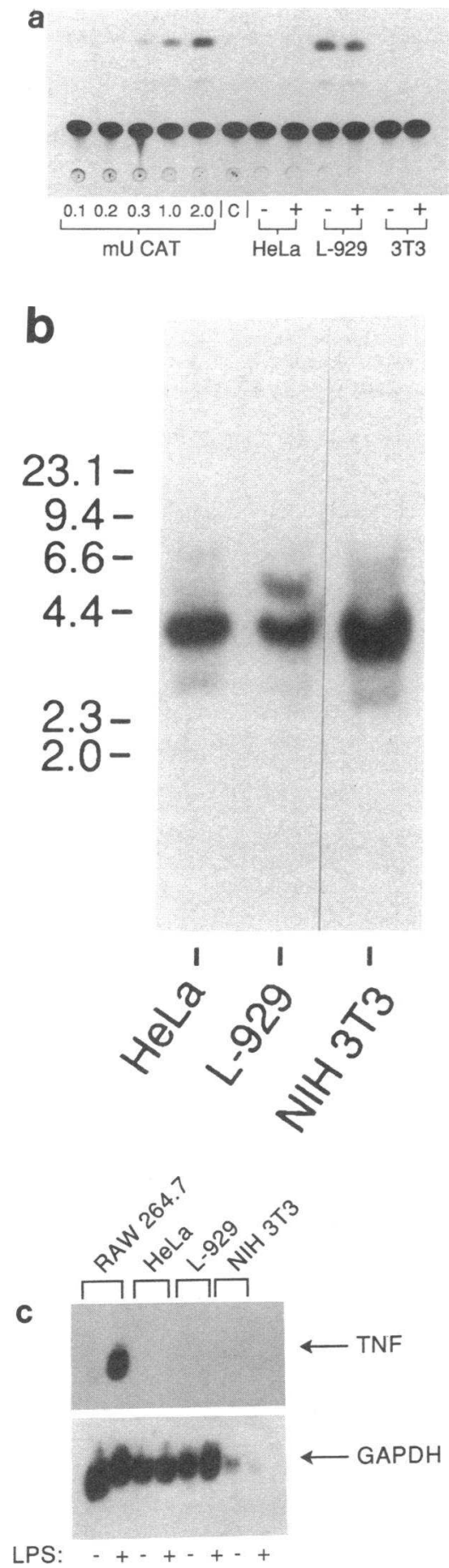
construct. Cells were induced with LPS for $2 \mathrm{~h}(+)$, or left noninduced $(-)$ before preparation of the RNA. RNA was carefully quantitated by electrophoresis in a methylmercuric hydroxide gel and staining with ethidium bromide before resolution in a formaldehyde gel for blot hydridization. Precisely equal quantities of RNA were loaded to each lane of the formaldehyde gel, electrophoresed, transferred to nylon, and probed sequentially for TNF and glyceraldehyde phosphate dehydrogenase (GAPDH) using riboprobes. $-80^{\circ} \mathrm{C}$ exposure time: $6 \mathrm{~h}$ for TNF; $90 \mathrm{~min}$ for GAPDH.

protein-encoding exons, or which lie at some distance from the TNF gene itself. Studies of the genetic requirements for tissuespecific expression in vivo are currently in progress.

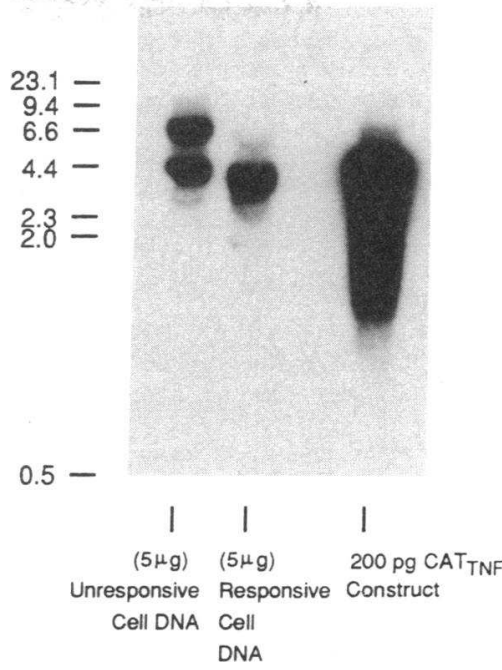

Figure 10. Southern blot analysis of genomic DNA obtained from transfected RAW 264.7 cells that maintained their ability to produce CAT in response to LPS, and from cells that lost their ability to produce CAT in response to LPS. $5 \mu \mathrm{g}$ of DNA from each cell type was digested to completion with $\mathrm{KpnI}$ and SmaI before electrophoresis and transfer to a nylon membrane. The blot was allowed to hybridize to a CAT riboprobe.

\section{Acknowledgment}

We are grateful to Ms. Patricia Thompson for her technical contributions to this work, and to Ms. Betsy Layton for her able secretarial assistance. We also indebted to Dr. Ernest Beutler for valuable discussions.

This study was supported, in part, by National Institutes of Health grant RO1 CA-45525.

\section{References}

1. Beutler, B., I. W. Milsark, and A. Cerami. 1985. Passive immunization against cachectin/tumor necrosis factor (TNF) protects mice from the lethal effect of endotoxin. Science (Wash. DC). 229:869-871.

2. Sheehan, K. C. F., N. H. Ruddle, and R. D. Schreiber. 1989. Generation and characterization of hamster monoclonal antibodies that neutralize murine tumor necrosis factors. J. Immunol. 142:3884-3893.

3. Tracey, K. J., Y. Fong, D. G. Hesse, K. R. Manogue, A. T. Lee, G. C. Kuo, S. F. Lowry, and A. Cerami. 1987. Anti-cachectin/TNF monoclonal antibodies prevent septic shock during lethal bacteraemia. Nature (Lond.). 330:662-666.

4. Tracey, K. J., B. Beutler, S. F. Lowry, J. Merryweather, S. Wolpe, I. W. Milsark, R. J. Hariri, T. J. Fahey, III, A. Zentella, J. D. Albert, G. T. Shires, and A. Cerami. 1986. Shock and tissue injury induced by recombinant human cachectin. Science (Wash. DC). 234:470-474.

5. Grau, G. E., L. F. Fajardo, P.-F. Piguet, B. Allet, P.-H. Lambert, and P. Vassalli. 1987. Tumor necrosis factor (cachectin) as an essential mediator in murine cerebral malaria. Science (Wash. DC). 237:1210-1212.

6. Piguet, P.-F., G. E. Grau, B. Allet, and P. Vassalli. 1987. Tumor necrosis factor/cachectin is an effector of skin and gut lesions of the acute phase of graft-vshost disease. J. Exp. Med. 166:1280-1289.

7. Piguet, P. F., M. A. Collart, G. E. Grau, Y. Kapanci, and P. Vassalli. 1989. Tumor necrosis factor/cachectin plays a key role in bleomycin-induced pneumopathy and fibrosis. J. Exp. Med. 170:655-664.

8. Jordana, M., C. Richards, L. B. Irving, and J. Gauldie. 1988. Spontaneous Sin vitro release of alveolar-macrophage cytokines after the intratracheal instillation of bleomycin in rats: characterization and kinetic studies. Am. Rev Respir. Dis. 137:1135-1140.

9. Fraker, D. L., H. N. Langstein, and J. A. Norton. 1989. Passive immunization against tumor necrosis factor partially abrogates interleukin 2 toxicity. $J$. Exp. Med. 170:1015-1020.

10. Kindler, V., A.-P. Sappino, G. E. Grau, P.-F. Piguet, and P. Vassalli. 1989. The inducing role of tumor necrosis factor in the development of bactericida granulomas during BCG infection. Cell. 56:731-740.

11. Beutler, B., J. Mahoney, N. Le Trang, P. Pekala, and A. Cerami. 1985. Purification of cachectin, a lipoprotein lipase-suppressing hormone secreted by endotoxin-induced RAW 264.7 cells. J. Exp. Med. 161:984-995.

12. Oliff, A., D. Defeo-Jones, M. Boyer, D. Martinez, D. Kiefer, G. Vuocolo, A. Wolfe, and S. H. Socher. 1987. Tumors secreting human TNF/cachectin induce cachexia in mice. Cell. 50:555-563.

13. Tracey, K. J., H. Wei, K. R. Manogue, Y. Fong, D. G. Hesse, H. T Nguyen, G. C. Kuo, B. Beutler, R. S. Cotran, A. Cerami, and S. F. Lowry. 1988. Cachectin/tumor necrosis factor induces cachexia, anemia, and inflammation. $J$. Exp. Med. 167:1211-1227.

14. Johnson, R. A., T. A. Waddelow, J. Caro, A. Oliff, and G. D. Roodman. 
1989. Chronic exposure to tumor necrosis factor in vivo preferentially inhibits erythropoiesis in nude mice. Blood. 74:130-138.

15. Cseh, K., and B. Beutler. 1989. Alternative cleavage of the cachectin/TNF propeptide results in a larger, inactive form of secreted protein. J. Biol. Chem. 264:16256-16260.

16. Kriegler, M., C. Perez, K. DeFay, I. Albert, and S. D. Lu. 1988. A nove form of TNF/cachectin is a cell surface cytotoxic transmembrane protein: ramifcations for the complex physiology of TNF. Cell. 53:45-53.

17. Loetscher, H., Y.-C. E. Pan, R. Gentz, M. Brockhaus, H. Tabuchi, and W. Lesslauer. 1990. Molecular cloning and expression of the human $55 \mathrm{kd}$ tumor necrosis factor receptor. Cell. 61:351-359.

18. Schall, T. J., M. Lewis, K. J. Koller, A. Lee, G. C. Rice, G. H. W. Wong, T. Gatanaga, G. A. Granger, R. Lentz, H. Raab, W. J. Kohr, and D. V. Goeddel. 1990. Molecular cloning and expression of a receptor for human tumor necrosis factor. Cell. 61:361-370.

19. Beutler, B., I. W. Milsark, and A. Cerami. 1985. Cachectin/tumor necrosis factor: production, distribution, and metabolic fate in vivo. J. Immunol. 135:3972-3977.

20. Beutler, B., N. Krochin, I. W. Milsark, C. Luedke, and A. Cerami. 1986. Control of cachectin (tumor necrosis factor) synthesis: mechanisms of endotoxin resistance. Science (Wash. DC). 232:977-980.

21. Tovey, M. G., J. Content, I. Gresser, J. Gugenheim, B. Blanchard, J. Guymarho, P. Poupart, M. Gigou, A. Shaw, and W. Fiers. 1988. Genes for IFNbeta-2 (IL-6), tumor necrosis factor, and IL-1 are expressed at high levels in the organs of normal individuals. J. Immunol. 141:3106-3110.

22. Han, J., T. Brown, and B. Beutler. 1990. Endotoxin-responsive sequences control cachectin/TNF biosynthesis at the translation level. J. Exp. Med. 171:465-475.

23. Shakhov, A. N., M. A. Collart, P. Vassalli, S. A. Nedospasov, and C. V. Jongeneel. 1990. kappaB-type enhancers are involved in lipopolysaccharide-mediated transcriptional activation of the tumor necrosis factor $\alpha$ gene in primary macrophages. J. Exp. Med. 171:35-47.

24. Chen, C., and H. Okayama. 1987. High-efficiency transformation of mammalian cells by plasmid DNA. Mol. Cell. Biol. 7:2745-2752.

25. Gorman, C. M., L. F. Moffat, and B. H. Howard. 1982. Recombinan genomes which express chloramphenicol acetyltransferase in mammalian cells. Mol. Cell. Biol. 12:1044-1051.
26. Sambrook, J., E. F. Fritsch, and T. Maniatis. 1989. Molecular Cloning. Cold Spring Harbor Laboratory, Cold Spring Harbor, NY.

27. Laemmli, U. K. 1970. Cleavage of structural proteins during the assembly of the head of bacteriophage T4. Nature (Lond.). 227:680-685.

28. Raschke, W. C., S. Baird, P. Ralph, and I. Nakoinz. 1978. Functional macrophage cell lines transformed by Abelson leukemia virus. Cell. 15:261-267.

29. Mannel, D. N., M. S. Meltzer, and S. E. Mergenhagen. 1980. Generation and characterization of a lipopolysaccharide-induced and serum-derived cytotoxic factor for tumor cells. Inf. Immunol. 28:204-211.

30. Mathison, J. C., E. Wolfson, and R. J. Ulevitch. 1988. Participation of tumor necrosis factor in the mediation of gram negative bacterial lipopolysaccharide-induced injury in rabbits. J. Clin. Invest. 81:1925-1937.

31. Fong, Y, K. J. Tracey, L. L. Moldawer, D. G. Hesse, K. B. Manogue, J. S. Kenney, A. T. Lee, G. C. Kuo, A. C. Allison, S. F. Lowry, and A. Cerami. 1989. Antibodies to cachectin/tumor necrosis factor reduce interleukin $1 \beta$ and interleukin 6 appearance during lethal bacteremia. J. Exp. Med. 170:1627-1633.

32. Michie, H. R., K. R. Manogue, D. R. Spriggs, A. Revhaug, S. O'Dwyer, C. A. Dinarello, A. Cerami, S. M. Wolff, and D. W. Wilmore. 1988. Detection of circulating tumor necrosis factor after endotoxin administration. N. Engl. J. Med. 318:1481-1486.

33. Collart, M. A., D. Berlin, J. D. Vassalli, S. DeKossodo, and P. Vassalli. 1986. Gamma interferon enhances macrophage transcription of the tumor necrosis factor/cachectin, interleukin 1, and urokinase genes, which are controlled by short-lived repressors. J. Exp. Med. 164:2113-2118.

34. Han, J., and B. Beutler. 1990. The essential role of the UA-rich sequence in endotoxin-induced cachectin/TNF synthesis. European Cytokine Network. 1:71-75.

35. Webb, G. C., and D. D. Chaplin, 1990 . Genetic variability at the human tumor necrosis factor loci. J. Immunol. 145:1278-1285.

36. Collart, M. A., P. Baeuerle, and P. Vassalli. 1990. Regulation of tumor necrosis factor alpha transcription in macrophages: involvement of four kappaBlike motifs and of constitutive and inducible forms of NF-kappaB. Mol. Cell. Biol. 10:1498-1506.

37. Economou, J. S., K. Rhoades, R. Essner, W. H. McBride, J. C. Gasson, and D. L. Morton. 1989. Genetic analysis of the human tumor necrosis factor alpha/cachectin promoter region in a macrophage cell line. J. Exp. Med. $170: 321-326$ 